\title{
Partidos políticos na América Latina
}

\author{
Manuel Alcántara Sáez \\ Universidade de Salamanca
}

Flavia Freidenberg

Universidade de Salamanca

\section{Resumo}

O argumento principal do artigo é mostrar que os partidos e sistemas partidários da América Latina são mais estáveis do que em termos gerais se costuma sustentar. Apesar da percepção hostil dos eleitores sobre os partidos, os sistemas de partidos apresentam certos níveis de estabilidade na região, afora casos como Venezuela e Peru, que parecem ser mais a exceção do que a regra. Foi realizada uma tipologia de quatro cenários em que se compara a oferta partidária na eleição fundacional pós-transição e na última eleição legislativa realizada em cada sistema.

Palavras clave: Partidos Políticos, Sistema partidários, América Latina, polarização, Latinobarómetro.

\begin{abstract}
The principal argument of this article is to show that the parties and the Latin American party system are more stable of which in general term usually it is maintained. In spite of the electorate hostile perception about the parties, the party system presents some level of stability in Latin America, with the exception of Venezuela and Peru. A four-dimension tipology compares the party offer in the fundational post-transition election and in the last legislative election in each system.

Key words: Party Politics, Party Systems, Latin America, polarization, Latinobarometro, effective number parties
\end{abstract}




\section{A importância dos partidos}

O avanço irrestrito da democracia nos últimos tempos supõe um processo triplo. A necessidade de articular regras de jogo assumidas pela maioria e que ao mesmo tempo compusessem espaços organizativos mínimos nos quais se realizasse a competição política. A incorporação da mobilização social através de formas de participação e de representação, e, finalmente, a criação de canais de seleção de pessoal político que liderasse e gerisse a política cotidiana. Estas três faces se referem a temas recorrentes da literatura das ciências sociais e aludem, em uma terminologia mais técnica, à institucionalização do regime político, à intermediação entre as demandas da sociedade e o poder, e à profissionalização da política.

Em um marco de poliarquia, em que predomine a livre e igualitária competição pelo poder mediante regras conhecidas e assumidas pela maioria por meio de processos eleitorais periódicos, a institucionalização, a intermediação e a profissionalização são elementos indispensáveis. Essas funções têm sido desempenhadas pelos partidos políticos, como claros eixos que entrelaçam de uma maneira estável e previsível a sociedade com o regime político. Independentemente do modelo de partido do que se parta, as funções desempenhadas de articulação e de agregação de interesses, de legitimação, de socialização, de representação e participação, e de formação de uma elite dirigente, com maior ou menor intensidade, continuam sendo vitais para o sistema político. ${ }^{1}$

Essa situação é comum a todos os sistemas políticos democráticos. No entanto, são notórias as diferenças existentes entre aqueles cujo desenvolvimento é de longa data, com um grau notável de consolidação, e os mais recentes. 0 papel venturoso dos partidos políticos se liga a sua operacionalidade funcional, e esta se encontra enormemente condicionada pela variável tempo e isso é mais importante ainda para o âmbito da competição interpartidária. Ou seja, a vida de um partido, seguindo certa comparação biológica, requer a existência de certas condições que estão ligadas à idéia de sobrevivência. A rotinização dos procedimentos, a

\footnotetext{
${ }^{1}$ Uma revisão profunda da literatura mostra que se chegou a um consenso sobre uma série de funções básicas exercidas pelos partidos. Entre as funções que se destacam cabe assinalar: a de proporcionar poder aos dirigentes (Weber, 1922/1944); a de competição eleitoral (Weber, 1922/1944; Downs, 1957; Sartori, 1976/1992); a de recrutamento de elites para tornar operativo o sistema político (Sartori, 1976/1996; Von Beyme, 1982/1986); a de socialização política porque oferecem informação básica e explicações aos cidadãos sobre como compreender a realidade (Alcántara, 1997) e a de representação e articulação de interesses de grupos sociais (Lipset e Rokkan, 1967; Cotarelo, 1985). Todas essas funções se desenvolvem de uma ou outra maneira, independentemente da concepção de partido que se sustente; seja como organizações para o recrutamento de votos eleitorais segundo Weber (1922/1992:9); partidos de integração de massas (Duverger, 1951/1992); como empresas eleitorais, seguindo os termos de Panebianco (1982/1990); partidos catch all como observou Kirchheimer (1980) ou a mais recente caracterização como partidos cartel desenvolvida por Katz e Mair (1995) .
} 
alternância de suas lideranças, desprendendo-se de adesões caudilhescas iniciais, a moderação de suas ofertas programáticas, a identificação clara e diferenciada por parte de um eleitorado mais ou menos fiel, são aspectos de um processo que se liga indefectivelmente ao tempo. No entanto, já se sabe que, em política, o tempo é um fator que em muitas ocasiões é escasso. Mais ainda, os processos de transição para a democracia são habitualmente impelidos por uma necessidade de urgência, de queimar etapas o mais rapidamente possível, de encontrar fórmulas mágicas que conspiram contra a própria idéia de que a institucionalização da política não é coisa de um dia.

A personalização da política, a aparente verticalidade no processo de tomada de decisões partidárias e as denúncias de que os partidos são oligarquias que representam cada vez menos os cidadãos levaram muitos a desprezar a importância dos partidos como instrumentos do sistema político, pondo em dúvida a capacidade mobilizadora e de representação dessas agremiações. Embora, em princípio, pareça que não há incentivos para que os partidos desenvolvam estratégias organizativas para forjar laços fortes com o eleitorado, nem tampouco estruturas que dêem sustentação aos dirigentes partidários, existem razões suficientes que ajudam a sustentar que os partidos continuam sendo instrumentos básicos do jogo político e estruturas de intermediação necessárias para o funcionamento do sistema.

Os eleitores os reconhecem ainda como referentes, apesar dos sentimentos antipartidários das elites, da abertura de muitos regimes políticos para a participação de setores independentes e da desconfiança manifesta de muitos cidadãos. Criticam-se os partidos, promovem-se modos de representação alternativos, mas até o momento não se propuseram outras formas de democracia que possam funcionar sem o concurso dos partidos. Por isso, eles continuam sendo os articuladores da competição eleitoral, criam um universo conceitual que orienta os cidadãos e as elites no que diz respeito à compreensão da realidade política, ajudam a fazer acordos em torno de políticas governamentais (muitas vezes de maneira conjuntural, como alianças fantasmas, e até por políticas específicas, mas o fazem), estabelecem ações para a produção legislativa; provêem de pessoal as instituições e tornam operativo o sistema político. Além disso, e como objetivo principal, ao querer ganhar eleições, ${ }^{2}$ contam com estratégias organizativas para

\footnotetext{
${ }^{2}$ Os partidos querem ganhar eleições e, como disse Downs (1957/1992, p. 96), formulam políticas para ganhar as eleições; não ganham as eleições para pôr em prática políticas. Mas é preciso dizer também que nem as organizações partidárias nem os políticos que as integram têm como única meta conseguir votos, já que em um mesmo partido convivem pessoas com interesses e objetivos diversos, a mobilização do apoio eleitoral com a pretensão de incrementar suas cotas de poder se apresenta como o objetivo principal dos políticos e suas organizações. Pode haver partidos que busquem desenvolver políticas de acordo com sua visão do mundo; que lhes interesse exercer a oposição e até outros que não se preocupem com a arena eleitoral, mas que prefiram manter sua própria sobrevivência como ator relevante dentro do sistema político. E mais
} 
mobilizar apoios que lhes permitam triunfar nessas eleições (ou conservar os apoios já conseguidos em oportunidades anteriores). ${ }^{3}$ E tudo isso não é pouca coisa.

\section{Os antecedentes históricos na América Latina}

Na América Latina, o universo partidário, seguindo pautas nacionais, é tão rico que se torna extremamente complexo fazer uma classificação dos partidos da região seguindo critérios relativos ao seu momento de fundação, ainda mais se se toma o período dos governos autoritários das décadas de 1970 e 1980 como um divisor de águas. Não obstante, faremos um breve relato da história recente para elucidar em que medida as transições, que tanto impulsionaram a reivindicação da democracia como única legitimidade política plausível, foram fonte de aparição ou, conforme o caso, revitalização dos partidos. Analiticamente, esse foi um momento histórico que separa profundamente a América Latina dos outros casos afetados pela terceira onda de democratização. ${ }^{4}$

No início dos processos de transição democrática (1978-1980), a América Latina contava com quatro cenários muito diferentes. O primeiro cobria os países com tradições partidárias sólidas, tanto em termos da existência de máquinas partidárias como de capacidade dessas máquinas para mobilizar o apoio de importantes setores da população. O segundo contemplava um modelo misto em que partidos antigos iriam coabitar com partidos novos surgidos do próprio processo de transição. O terceiro enquadrava os casos definidos pela manutenção da existência de organizações, mas historicamente vazias do ponto de vista político e social. Finalmente, o quarto estava presente nos países em que, somando-se a debilidade histórica partidária aos efeitos dos últimos tempos dos governos autoritários, mal havia um marco mínimo de partidos (Ver Quadro I).

No primeiro caso, sempre tomando como referência o pano de fundo das transições para a democracia, estavam os países do Cone Sul (Argentina, Chile e Uruguai). Neles, o universo partidário praticamente respeitava o mesmo esquema

ainda, pode haver políticos que procurem alcançar alguma combinação desses objetivos ou que em momentos diversos tenham objetivos diferentes, isto é, que experimentem um deslocamento de seus objetivos. Mesmo assim, esta idéia de ver os partidos como grupos que buscam cotas de poder se encontra amplamente difundida na literatura. Diversos autores como Weber (1922/1944), Duverger (1951), Downs (1957), Sartori (1976/1992), Kirchheimer (1980), Von Beyme (1982/1986) e Aldrich (1995) sustentaram essa premissa.

${ }^{3}$ A idéia de que os partidos utilizam estratégias para mobilizar apoios eleitorais se baseia na premissa de que os partidos têm como meta principal ganhar eleições. Desse ponto de vista, relativamente novo na literatura sobre o tema, o partido é visto como um sistema político em si mesmo (Katz e Mair, 1995), que tem seu próprio processo de tomada de decisões, seu próprio sistema eleitoral e atores participantes (Eldserveld, 1964). As estratégias são entendidas como os cursos de ação (decisões e atividades) organizativas que os dirigentes (ou estrategistas) projetam para alcançar suas metas.

${ }^{4}$ Após os processos de mudança política que a América Latina sofreu na década de 1970, começaram a proliferar os trabalhos que estudaram os partidos como atores principais da transição, na qual, em muitos casos, as estruturas partidárias exerceram o papel de ponta de lança da desejada democratização (Garretón, 1993; Cavarozzi, 1995; Alcántara, 1994; Dutrénit, 1998). 
anterior à quebra da democracia: radicais e justicialistas na Argentina; socialistas, democrata-cristãos, radicais e conservadores no Chile; e colorados, blancos e frente-amplistas no Uruguai, eram uma continuação da política nacional de inícios da década de 1970, absorvendo valores superiores a 90 por cento de apoio eleitoral. Em um primeiro momento pós-transição, este também seria o caso do Peru, já que os dois partidos que se alternaram no poder na década de 1980 (APRA e Ação Popular) eram anteriores ao processo autoritário, embora posteriormente o próprio sistema de partidos, como se verá mais adiante, sofresse um dos cataclismos mais sérios da região.

O segundo, mais complexo, reunia partidos nascidos em meados do século $X X$ que mantinham uma estrutura muito sólida e em torno dos quais o novo sistema político democrático ainda girava. Tal era o caso do Movimento Nacionalista Revolucionário (MNR) na Bolívia e do Partido dos Trabalhadores (PT) no Brasil. Eles conviveram com uma variedade de novos partidos surgidos, seja durante o período autoritário, seja durante a própria transição. São exemplos os casos de ADN e MIR e, mais adiante, CONDEPA e UCS na Bolívia, e do PMDB, PSDB, PDT e PFL no Brasil, entre outros. Pode-se enquadrar também neste caso o Equador, que reproduz o sistema de partidos anterior ao rompimento da democracia. O PSC foi criado em 1951 como MSC, e como PSC em 1967; a DC (que é o tronco fundador e fundamental da DP) em 1964; a ID em 1967 e somente o PRE em 1983, depois do desaparecimento de dois líderes que deixaram um vazio de poder na tendência populista. Esses partidos conviveram em um primeiro momento com o CFP, PLRE e PCE, todos anteriores à ruptura democrática.

O terceiro caso acolheria o Paraguai, onde a presença contínua da fraude eleitoral marcou a existência da Ação Nacional Republicana (Partido Colorado) e do Partido Liberal Radical Autêntico. Somente depois das primeras eleições constitucionais de 1993, o jogo partidário ficou mais claramente legitimado. Algo similar se poderia dizer dos Partidos Liberal e Nacional de Honduras. Essa situação também se poderia ampliar para o caso da Nicarágua, embora parcialmente, no que tange ao Partido Liberal, ou ao Panamá, com o PRD e o Partido Arnulfista.

Do último grupo fariam parte os sistemas de partidos em que houve um processo muito claro de refundação paralelo ao processo de transição. Isso parece evidente em El Salvador, onde ARENA e FMLN são filhos do conflito bélico, e na Guatemala, onde FRG, PAN e URNG têm origem semelhante. O mesmo vale parcialmente para a Nicarágua, com o FSLN, e para a República Dominicana, embora aqui a presença do PRD datasse da ditadura trujillista.

No entanto, nem todos os países latino-americanos entram nessa tipologia. Ficam de fora os três casos que tiveram processos transicionais anteriores: Costa 
Rica, Colômbia e Venezuela; e aqueles dois, Cuba e México, que viveram imersos, este segundo até muito recentemente, em um regime de partido único.

Tudo isso permite fazer uma caracterização dos partidos em uma linha que enfatiza a grande heterogeneidade reinante na América Latina quando chegou à região a terceira onda de democratização. Paralelamente, e embora se deva levar em conta o efeito transicional, este fato sugere a necessidade de aprofundar outras variáveis explicativas do desenvolvimento partidário, suas transformações e suas eventuais crises que levam à eliminação de uns e ao nascimento de outros.

\begin{tabular}{|c|c|c|c|c|}
\hline \multicolumn{3}{|c|}{$\begin{array}{c}\text { Sistema de partidos no início da transição. } \\
\text { Partidos com maior apoio na eleição } \\
\text { fundacional legislativa }\end{array}$} & \multicolumn{2}{|c|}{$\begin{array}{c}\text { Sistemas de partidos na atualidade. } \\
\text { Partidos com maior apoio na última } \\
\text { eleição legislativa }\end{array}$} \\
\hline PAIS & Ano & Partidos & Ano & Partidos \\
\hline \multicolumn{5}{|l|}{ Grupo I } \\
\hline Argentina & 1983 & UCR-PJ & 1999 & UCR-FREPASO - PJ \\
\hline Chile & 1989 & $\begin{array}{l}\text { Concertación - Unión por } \\
\text { el Progreso de Chile }\end{array}$ & 1997 & $\begin{array}{l}\text { Concertación - Unión por } \\
\text { el Progreso de Chile }\end{array}$ \\
\hline Uruguai & 1984 & PC-PN-Frente Amplio & 1994 & PC-PN - Frente Amplio \\
\hline Peru & 1980 & APRA - AP & 2000 & Perú 2000- Perú Posible \\
\hline \multicolumn{5}{|l|}{ Grupo // } \\
\hline Bolívia & 1985 & MNR-ADN & 1997 & $\begin{array}{l}\text { MNR-ADN-MIR- } \\
\text { CONDEPA-UCS }\end{array}$ \\
\hline Brasil & 1986 & $\begin{array}{l}\text { PFL-PMDB- } \\
\text { ARENA/PDS/PPR }\end{array}$ & 1998 & PFL-PSDB-PMDB-PT. \\
\hline Equador & 1978 & CFP-ID-PCE & 1998 & $\begin{array}{l}\text { DP.PSC-PRE-ID-MUPP. } \\
\text { NP }\end{array}$ \\
\hline \multicolumn{5}{|l|}{ Grupo III } \\
\hline Paraguai & 1993 & ANR-PC - PLRA & 1998 & ANR-PC - PLRA \\
\hline Honduras & 1981 & PLH.PNH & 1997 & PLH.PNH \\
\hline Nicarágua & 1984 & FSLN & 1996 & FSLN-ALIANZA LIBERAL \\
\hline Panamá & 1994 & PRD-ARNULFISTA & 1999 & PRD-ARNULFISTA \\
\hline \multicolumn{5}{|l|}{ Grupo IV } \\
\hline El Salvador & 1982 & ARENA.PDC-PCN & 1997 & ARENA-FMLN \\
\hline $\begin{array}{l}\text { Rep. } \\
\text { Dominicana }\end{array}$ & 1978 & PR/PRSC-MMP & 1998 & PRD-PLD \\
\hline Guatemala & 1985 & DCG-UCN-MLN & 1999 & FRG-PAN \\
\hline Colômbia & 1982 & PC.PL & 1998 & PC.PL \\
\hline Costa Rica & 1982 & PLN. UNIDAD & 1998 & PLN- PUSC \\
\hline Venezuela & 1973 & AD. COPEI & 2000 & AD-COPEI -MVR - MAS \\
\hline México & 1985 & PRI & 2000 & PRI - PAN- PRD \\
\hline
\end{tabular}

* No caso em que houve eleição para duas câmaras, inclui-se o dado da Câmara Baixa.

** O critério de inclusão é que os partidos tiveram una representação majoritária na Câmara.

Fonte: Elaboração própria a partir de dados extraídos de Manuel Alcántara Sáez: Sistemas Políticos de América Latina. Madri, Tecnos, 1999. 


\section{As mudanças nos partidos da América Latina entre 1980 e 2000}

Ao longo do período de democratização dos sistemas políticos latinoamericanos acontecido depois das transições políticas, em alguns casos, e de continuidade, para outros, os partidos políticos da região sofreram profundas mutações que se baseiam em aspectos tanto endógenos como exógenos, em questões de alcance estritamente político institucional, ou em outras de conteúdo social ou econômico.

Os elementos endógenos centraram-se em questões tradicionais como as relativas a lideranças mais ou menos caudilhescas, a enfrentamentos entre os Poderes do Estado, ao impacto da corrupção. Por seu lado, o fator exógeno por excelência foi a derrocada do socialismo real e a perda de um referente sólido ideológico e prático para grandes setores da esquerda latino-americana. Entre as questões de caráter político-institucional que tinham a ver com as modificações registradas no universo partidário, se encontravam as mudanças realizadas nos próprios textos constitucionais, as leis partidárias e as leis eleitorais. Nenhum país latino-americano deixou de fazer essas modificações, com maior ou menor profundidade, durante esse período. Finalmente, as questões de outra índole não estritamente políticas também estiveram na origem das mudanças acontecidas, fosse como conseqüência da crise econômica que assolou a região durante a década de 1980 e que enterrou definitivamente o modelo de substituição de importações e a centralidade do Estado vigentes quase durante meio século, ${ }^{5}$ fosse como resultado da aparição de valores pós-materialistas e das mudanças registradas nas sociedades.

A partir de uma perspectiva descritiva, sem utilizar índice algum de volatilidade que reforce o argumento de uma posição mais empírica, constata-se que as mudanças ocorridas nos sistemas de partidos latino-americanos entre 1980 e 2000, em termos da continuidade das mesmas siglas partidárias, somente afetam um número muito limitado de casos. Com exceção de Brasil, Peru e Venezuela, os outros países continuam mostrando uma estrutura partidária muito similar no final do período indicado à que tinham em seu início. A mudança radical de pressupostos programáticos que afetou muito os velhos defensores do populismo mais ativo não incluiu uma transformação profunda na cúpula dirigente, nem nas bases sociais de apoio. Isso fica evidente nos casos do PJ da Argentina e do PRI do México, especialmente durante os governos de Carlos Menem e de Carlos Salinas de Gortari. A relativa continuidade na composição dos sistemas de partidos é um aspecto surpreendente que contradiz a visão que habitualmente se oferece da

\footnotetext{
${ }^{5}$ Embora Uruguai e Costa Rica sejam uma exceção nesta situação.
} 
existência de mudanças dramáticas, ou da derrocada da ordem anteriormente existente.

Por outro lado, a continuidade observada permite matizar a suposta crise dos partidos, na medida em que se "estes continuam sendo os que eram", sua própria existência, graças aos processos eleitorais, invalida a tese genérica da rejeição dos eleitores. A classe política continua, portanto, mantendo as velhas siglas, sem procurar outro tipo de reacomodação. Embora isso, como se verá mais adiante, não minimiza a percepção hostil que a população continua tendo dos partidos.

De qualquer modo, é um fato que a média dos partidos latino-americanos é estável e que as profundas mudanças acontecidas no Peru e na Venezuela durante a década de 1990 são a exceção, e não a regra. Nesses dois países pode se falar, sem nenhuma dúvida, de uma refundação do sistema partidário segundo um esquema funcional para os interesses das lideranças bonapartistas de seus respectivos presidentes. Por outro lado, as expectativas geradas em outros países com respeito ao nascimento de novos partidos que pudessem transformar radicalmente os diferentes sistemas políticos foram pouco a pouco desenganadas. Primeiro, foi o M19 colombiano que não soube manter o impulso que o levou a posicionar-se como uma terceira força na constituinte de 1991; depois, o PRD mexicano, que deixou de ser alternativa nas eleições de 2000, e a própria FREPASO argentina, muito diluída no seio da Aliança contra a histórica UCR. Uma situação parecida ocorreu no Equador com o Movimento Unidade Pachakutik-Nuevo País, que embora tenha se posicionado como a terceira força em sua estréia eleitoral de 1996, obtendo quinze assentos no Congresso da República, precisa ainda mostrar qual vai ser seu papel e o apoio que os cidadãos lhe darão devido a seus constantes comportamentos que bordejam o limite do sistema.

\section{Três características sistêmicas dos partidos na América Latina ao final do século XX}

A longa lista de variáveis presentes, conforme o que disse anteriormente, requereria um tratamento alheio ao interesse deste artigo, que se centra na busca de um diagnóstico mais simples baseado na identificação de quais variáveis, entre as citadas, estiveram no vértice da mudança e chegaram a gerar o estado atual das coisas. Três aparecem como as de maior força explicativa por sua capacidade de integrar as restantes. Trata-se do formato numérico do sistema de partidos, de sua polarização ideológica e do apoio social que recebem. Todas elas compõem uma proposta que gira em torno de não diferenciar o problema, no âmbito do estudo dos partidos, em duas dimensões: a referida aos sistemas de partidos e a atinente à vida interna dos próprios partidos, algo já tradicional nas análises dos politólogos 
que concedem sempre mais atenção ao primeiro aspecto do que ao segundo; desse modo, se aceita não perder de vista a retroatividade de ambas as dimensões. ${ }^{6}$

\section{O formato numérico dos sistemas de partidos}

Uma questão relevante se refere ao formato numérico dos sistemas de partidos que tenta projetar a quantificação dos mesmos no sistema político. Se tomarmos o Poder Legislativo como âmbito primordial da competição política, uma vez dirimida a contenda eleitoral, e se analisarmos o número de partidos ali existentes, realizando uma relativa ponderação em função de seu peso diferente (isto é o que vem a ser o conceito de número efetivo de partidos ${ }^{7}$ ), constatamos que a América Latina tende ao multipartidarismo. O Quadro 2, que resume os valores médios do número efetivo de partidos para a década de 1990, indica que apenas

\footnotetext{
${ }^{6} \mathrm{O}$ estudo dos partidos políticos esteve concentrado em aspectos bastante distintos aos relacionados com a organização e o funcionamento interno. Pode-se dizer que na academia não houve realmente interesse em estudar o que ocorre dentro das agrupações partidárias. Além dos trabalhos realizados de uma perspectiva histórica (Di Tella, 1993; Dutrénit e Valdez, 1994; Malamud, 1995), o enfoque dominante privilegiou a análise dos partidos na relação com seu ambiente. Neste sentido, as pesquisas centraram seu interesse na vinculação dos partidos com seu entorno, seja em sua vinculação com outras organizações partidárias, por exemplo, com relação à competição eleitoral (Nohlen, 1993; Alcántara, 1996); em sua interação no marco do sistema de partidos e sua ancoragem na sociedade civil (Mainwaring e Scully, 1995); em sua relação com as instituições do sistema político (Mainwaring e Soberg Shugart, 1997) ou, como já se observou, enquanto promotores da democratização. Com a reiterada realização de processos eleitorais, os autores concentraram ainda mais suas análises no rendimento eleitoral dos partidos e naqueles aspectos vinculados a sua participação nas eleições, por exemplo, a realização de campanhas eleitorais e pesquisas de opinião. Mas as dificuldades que as organizações partidárias encontravam para satisfazer as demandas dos cidadãos em cenários de crise econômica, de apatia e desencanto com a atividade política, levaram ao surgimento de outsiders políticos, personalidades que embora chegassem ao poder graças aos partidos, atuavam à margem deles (Perelli, Picado e Zovatto, 1995; Mayorga, 1995). Isso levou muitos estudiosos a falar de uma crise de representação dos partidos (Manz e Zuazo, 1998) e conduziu a investigação sobre o surgimento de novos mecanismos de representação, como os (velhos e novos) movimentos sociais, que procuravam superar os partidos como estruturas de intermediação política entre os cidadãos e o Estado. É possível encontrar trabalhos que concentraram sua análise em algum aspecto relacionado com a organização interna, como o financiamento eleitoral e não eleitoral (Álvarez, 1997; Fernández Rubio, 1997; Del Castillo e Zovatto, 1998; Ramos Rollón, 1998) ou a disciplina interna e a presença de facções (Morgenstern, 1996), mas os estudos de partidos como unidades de análise são escassos (Coppedge, 1994; Jimenez Polanco, 1995; Levitsky, 1997), assim como tampouco se realizaram investigações tanto teóricas como empíricas de caráter sistemático comparado entre diversos países da região ou entre partidos de um mesmo sistema político que analisem a organização interna e o tipo de funcionamento das organizações partidárias a partir de um mesmo esquema analítico de aproximação. Neste sentido, uma investigação recente que centra a análise nos partidos como mini- sistemas políticos procura aprofundar a discussão do funcionamento interno das organizações partidárias. Ver Alcántara e Freidenberg (2001).

${ }^{7}$ A fragmentação eleitoral pode ser medida através de dois índices: o de fracionalização (Rae, 1977) e o do número efetivo de partidos (Laakso e Taagepera, 1979). A fórmula para calcular o índice de fracionalização a partir da proposta de Rae é a seguinte:
}

$$
\mathrm{F}=1-\left(\Sigma \mathrm{T}_{\mathrm{i}}^{2}\right)
$$

Em que $\mathrm{T}_{\mathrm{i}}=$ é a porcentagem de votos (ou de cadeiras) de cada partido. Este índice permite apreciar a relação existente entre o número de partidos e seu tamanho, se aplica tanto ao campo eleitoral (votos) como ao legislativo (cadeiras) e abarca teoricamente desde zero, que seria a situação hipotética em que todos os votantes se inclinariam pelo mesmo partido ou que todos os legisladores pertencessem ao mesmo partido, o que supõe uma ausência de competição, até 1 , que é a situação hipotética em que todos os votantes se inclinariam por distintos partidos ou que todos os parlamentares pertencessem a partidos diferentes e que, portanto, houvesse tantas opções partidárias quanto casos em competição. O número efetivo de partidos proporciona a mesma informação que o índice de fracionalização sobre o sistema de partidos, mas de uma maneira mais simples, já que permite apreciar melhor quantos partidos competem eleitoralmente e quantos no estão presentes no Congresso. A partir dessa fórmula, pode-se calcular $\mathrm{N}$ do seguinte modo: $\mathrm{N}=1 /(1-\mathrm{F})$. 
um número muito reduzido de países se aproxima do bipartidarismo puro que traduz com mais simplicidade a lógica governo-oposição (Costa Rica, Honduras e Paraguai). Ao contrário, todos os demais países estão imersos em uma situação cujo alto número de partidos implica habitualmente duas coisas: uma rotação mais multiforme na hora de obter êxitos eleitorais e a necessidade de realizar acordos amplos que levem a governos de coalizão, circunstância que ocorre fundamentalmente em Argentina, Bolívia, Brasil, Chile e Uruguai.

Em algum momento se observou o lado negativo para a governabilidade de um excesso de ofertas partidárias, na medida em que confunde o eleitorado, que pode chegar a ter dificuldades para diferenciá-las, e na propensão a tornar mais complicada a existência de maiorias sólidas, claras e estáveis. Não obstante, tanto a tradição eleitoral de incorporar a representação proporcional nas eleições legislativas como a própria heterogeneidade das sociedades latino-americanas refletem uma situação distinta desse suposto ideal.

QUADRO 2

Médias do número efetivo de partidos legislativos

\begin{tabular}{|l|c|c|}
\cline { 2 - 3 } \multicolumn{1}{c|}{} & Primeira metade da década de 1990 & Durante a década de 1990 \\
\hline Bolívia & 4,1 & 4,4 \\
\hline Brasil & 8,5 & 7,3 \\
\hline Colômbia & 2,2 & 2,9 \\
\hline Costa Rica & 2,2 & 2,3 \\
\hline Chile & 5,1 & 5,1 \\
\hline Equador & 6,6 & 5,3 \\
\hline El Salvador & 3,0 & 3,3 \\
\hline Guatemala & 3,5 & 3,2 \\
\hline Honduras & 2,0 & 2,1 \\
\hline México & 2,2 & 2,4 \\
\hline Nicarágua & 2,0 & 3,3 \\
\hline Panamá & 4,3 & 3,8 \\
\hline Paraguai & 2,2 & 2,0 \\
\hline Peru & 4,3 & 3,3 \\
\hline R.Dominicana & 2,8 & 2,9 \\
\hline Uruguai & 3,3 & 3,2 \\
\hline Venezuela & 3,7 & 4,9 \\
\hline Total regional & 3,7 & 3,6 \\
\hline
\end{tabular}

Dados da primeira metada da década tomados de Manuel Alcántara, "Elecciones, Electores y Partidos en América Latina en la década de 1990", in América Latina Hoy 13 (maio) : 7-16 (Madri e Salamanca: SEPLAInstituto de Estudios de Iberoamérica y Portugal). Fonte: Elaboração própria. 


\section{A polarização ideológica dos partidos políticos latino-americanos}

Essa heterogeneidade das sociedades latino-americanas recém-citada se expressa numa polarização ideológica ${ }^{8}$ relativamente alta entre os partidos políticos presentes no Poder Legislativo mais distanciados na escala esquerda-direita. De acordo com o conteúdo do Quadro 3, a média latino-americana da polarização ideológica, segundo a escala de autopercepção, se situa em 2,5 pontos e a realizada de conformidade com a escala de percepção dos outros se estabelece em 4,8 pontos. Ambas deixam espaço para a inclusão de fórmulas partidárias intermediárias, sendo o próprio grau de polarização um incentivo para sua inclusão.

\section{QUADRO 3}

Distâncias na polarização ideológica entre os partidos parlamentares mais extremos

\begin{tabular}{|l|l|l|}
\hline Argentina & FREPASO-PJ & $1,6(3,2)$ \\
\hline Bolívia & CONDEPA-AND & $3,6(4,0)$ \\
\hline Colômbia & PL-PC & $1,8(2,0)$ \\
\hline Costa Rica & PLN-PUSC & $\cdot(3,2)$ \\
\hline Chile & PS-UDI & $3,8(6,3)$ \\
\hline Equador & PACHAKUTIK-PSC & $3,4(3,9)$ \\
\hline EI Salvador & FMLN-ARENA & $\cdot(8,2)$ \\
\hline Guatemala & MLN-FDNG & $\cdot(6,5)$ \\
\hline Honduras & PL-PN & $\cdot(2,6)$ \\
\hline México & PRD-PAN & $3,1(6,2)$ \\
\hline Nicarágua & FSLN-AL & $\cdot(6,8)$ \\
\hline Paraguai & PEN-ANR & $1,9(1,8)$ \\
\hline Peru & CAMBIO90-APRA & $2,1(4,2)$ \\
\hline R. Dominicana & PLD-PRSC & $2,0(2,7)$ \\
\hline Uruguai & FA.PN & $2,7(4,8)$ \\
\hline Venezuela & MAS-COPEI & $2,0(3,1)$ \\
\hline Média regional & & $2,5(4,8)$ \\
\hline
\end{tabular}

A polarização é medida em uma escala na qual 1 é esquerda e 10 direita de acordo com a subtração dos valores médios dos partidos que se situam no extremo ideológico do arco parlamentar.

Sem parênteses são as distâncias entre autopercepções, entre parênteses são distâncias de percepções dos outros.

Fonte: Manuel Alcántara (dir.). Proyecto de Elites Latinoamericanas (PELA). Universidad de Salamanca (19942000).

\footnotetext{
${ }^{8}$ A partir da autolocalização ideológica dos membros dos partidos é factível conhecer quais partidos estão mais próximos e quais mais distantes e até que ponto partidos adjacentes são similares ou estão próximos uns de outros (Sartori e Sani, 1976/1992:438). Referir-se à polarização supõe também pensar em um modelo espacial como o proposto por Anthony Downs (1957) para vincular a ideologia, os partidos e os eleitores. Diz-se que dois grupos são "pólos separados" para indicar que suas atitudes são tão marcadamente distintas que não poderiam encontrar-se mais distantes umas de outras (Sani e Shabad, 1986: 590). Podemos usar duas medidas para conhecer a polarização do sistema de partidos: a distância e a superposição. Quanto maior for a distância e menor a superposição ideológica, o sistema de partidos estará mais polarizado. Ao contrário, quanto menor for a distância e maior a superposição, mais moderado será o sistema.
} 
Como se indicou acima, uma excessiva polarização ideológica costuma ser interpretada como uma situação que aponta para uma ruptura próxima do sistema político. O grau de polarização permite pressupor a predisposição da elite política para compactuar políticas que favoreçam a ação de governo (fórmulas de consenso) ou, ao contrário, que dificultem a ação governamental (dissenso). A polarização está vinculada à governabilidade (Alcántara, 1995, p.387), como também é uma variável de grande conteúdo explicativo no momento de estudar a estabilidade do sistema democrático, sua eficácia, atividade e viabilidade (Sartori \& Sani, 1976/1992). Não obstante, os dados de polarização também podem ter a leitura de que traduzem uma situação positiva em que finalmente o sistema político foi capaz de levar a cabo uma função integradora. El Salvador, Nicarágua, Chile e México são os casos com um maior grau de polarização. Os primeiros refletem a integração da guerrilha no sistema político sob a forma de um partido. No Chile, projeta-se a profunda divisão que sua sociedade sofreu durante o longo período autoritário, enquanto que no México, se refletem as tensões anteriores à histórica mudança de julho de 2000.

Contudo, se em alguns países, apesar dos níveis de polarização, a política começa a se encaminhar através de espaços de competição e diálogo democrático, em muitos outros a política parece ser um diálogo de surdos. Um exemplo disso parece ser o Equador, onde os estereótipos, certa irresponsabilidade das elites e a presença de fraturas latentes (cleavages) que não terminaram de incorporar-se na comunidade nacional - como a regional e a étnica - conduzem a um clima de tensão política constante. Nesses casos, a polarização pressiona no sentido da ingovernabilidade do sistema político.

\section{O apoio social aos partidos políticos latino-americanos}

Diante do exposto, pareceria que os partidos latino-americanos gozam de boa saúde. No entanto, os distintos analistas assinalam como um de seus principais problemas a rejeição que suscitam entre a população, a baixíssima valoração que recebem, de acordo com as pesquisas de opinião, quando se pergunta sobre diferentes instituições e os partidos são classificados indefectivelmente no último lugar. Esta circunstância se reflete também no Quadro 4 e o no Gráfico 1 que mostra que apenas 21 por cento dos latino-americanos têm muita ou alguma confiança nos partidos. Países como Venezuela, Equador, Argentina, Panamá e Peru estão entre os que seus cidadãos manifestam menor apoio aos partidos, enquanto que em lugares como Costa Rica ou México, os partidos são mais bem considerados.

Não obstante, essa avaliação convencional sobre os partidos deve ser matizada. Em primeiro lugar, é essencial levar em conta outro tipo de respostas maciças positivas a perguntas do tipo de "se o país pode funcionar sem políticos" 
(ver Quadro 5 e Gráfico 2) ou os próprios valores das cifras de participação eleitoral, que depois de décadas de seca, manipulação eleitoral e inclusive de ausência total de prática eleitoral, e embora continuem existindo numerosos problemas técnicos na administração eleitoral (censo, etc.), se situam claramente acima de 60 por cento da população com idade de votar (ver Quadro VI e Gráfico 3). Embora se deva levar em conta que em muitos países o sufrágio é obrigatório, o que relativizaria esse tipo de afirmação, não se deve esquecer que as penas por não participar não costumam ser aplicadas pelos poderes públicos. Em países como Uruguai, Nicarágua, Argentina, Costa Rica e Bolívia, os cidadãos acreditam que o país não poderia funcionar sem partidos e este tipo de afirmação revaloriza o papel dessas instituições. Alguns dirão que essa afirmação responde à ausência de mecanismos alternativos aos partidos políticos na tarefa de representação cidadã. $E$ é certo, uma vez que até o momento, com algumas exceções, ${ }^{9}$ os partidos não puderam ser substituídos na hora de representar as demandas dos cidadãos e no exercício do governo. Portanto, continuam sendo os vínculos entre regime político e cidadãos.

Além disso, os dados mostrados equiparam-se aos do Quadro 7, segundo o qual 55 por cento dos latino-americanos pensam que o voto é um instrumento para mudar as coisas no futuro, porcentagem que viria a coincidir com a da média da participação eleitoral. Na maioria dos países latino-americanos, o voto continua sendo o instrumento por meio do qual se escolhem os políticos e, através deles, os partidos. As preferências que se manifestam por pessoas, como alguns militantes e dirigentes partidários apontaram em diversas entrevistas realizadas, ${ }^{10}$ terminam por converter-se em apoio às estruturas partidárias.

De qualquer modo, convém analisar os dados por países para constatar as grandes diferenças existentes. Três dos cinco países cujos entrevistados mostram em maior grau que não têm nenhuma confiança nos partidos - Venezuela, Equador e Peru - são os que em 2000 enfrentavam a maior crise política de toda a região. Como já se mencionou, Venezuela e Peru refundavam seus canais de representação popular e o Equador era vítima de uma insólita espiral de instabilidade política, com cinco presidentes em três anos. Esses países experimentaram profundas crises político-partidárias, ao ponto de, no caso de Venezuela e Peru, chegar a refundar-se o tipo de vínculo existente entre os partidos e os cidadãos. Por isso mesmo, é interessante observar que é precisamente nesses países que os cidadãos acreditam em maior porcentagem que seu voto conta para mudar as coisas no futuro (Quadro 8). Essa combinação de crise, mudança partidária e otimismo no ato de votar por parte dos cidadãos mostra uma interessante ambigüidade na política desses países.

\footnotetext{
${ }^{9}$ Neste caso, nos referimos às tentativas de reforma política realizadas no Equador, destinadas a abrir a participação para os independentes e tirar o monopólio da representação dos partidos políticos. Neste sentido, ver Freidenberg e Alcántara (2001).

${ }^{10}$ No Projeto de Pesquisa sobre "Partidos Políticos na América Latina" muitos dos militantes responderam neste sentido.
} 
Precisamente, a valorização do voto nesses dois países de alto nível de crises partidárias coincide com aquela que ocorre em países onde existe uma tradicional estabilidade do sistema de partidos, como Uruguai ou Argentina. Essas valorizações também se manifestaram em Paraguai, Nicarágua, Brasil e El Salvador. Ao mesmo tempo, países como Bolívia, Colômbia, México ou Guatemala se apresentam como casos em que a população se divide em partes mais ou menos iguais quanto à possibilidade de que o voto mude as coisas no futuro. Ainda assim, a participação eleitoral e o voto continuam sendo instrumentos reconhecidos e valorizados do sistema político, o que abona ainda mais a atuação dos partidos.

\section{Conclusões}

O argumento central deste artigo está em destacar que os partidos são importantes e contam na vida política da América Latina. Apesar dos prognósticos, das percepções gerais dos cidadãos e de algumas análises, a tendência geral que se manifesta é de certa estabilidade na configuração dos sistemas partidários latinoamericanos. Na maior parte dos sistemas poliárquicos, as elites partidárias que refundaram as regras do jogo político continuam sendo parte da vida política de cada país e, através desses partidos, continuam tornando o sistema político operativo e o legitimando.

Como já se mencionou nas páginas anteriores, os partidos na América Latina continuam estruturando a competição e dando forma aos resultados eleitorais; continuam criando o universo conceitual que orienta os cidadãos e as elites no que se refere à compreensão da realidade política, ajudam a costurar acordos em torno de políticas governamentais (muitas vezes de maneira conjuntural, como alianças fantasmas e até por políticas específicas, mas o fazem), estabelecem ações para a produção legislativa; provêm de quadros as instituições e, com tudo isso, tornam o sistema político operativo. Os partidos continuam sendo os atores principais na estruturação da dinâmica política latino-americana, apesar de certas exceções de sistemas pontuais e do papel que cada vez mais têm os meios de comunicação de massa e alguns novos movimentos sociais.

Dada a centralidade que os partidos continuam tendo, é interessante pensar na necessidade de conhecer ainda mais como funcionam internamente. Isso nos leva a mudar a unidade de análise dos sistemas partidários para os partidos e observar o modo como interagem os diversos atores que os integram; suas características e sua natureza; sua participação nos processos de tomada de decisões; o modo como se produz a política e esta se exerce. Se os partidos continuam sendo centrais no sistema político, então será preciso aprofundar seu estudo. Uma linha de trabalho que surge como proposta é a que centra a unidade de análise nas estratégias que desenvolvem para alcançar suas metas. Ao querer 
ganhar eleições, contam com estratégias organizativas (decisões e atividades) que Ihes ajudam a conseguir seus fins. Quem sabe, ao aprofundar este tipo de análise, se conheça mais ainda o modo como se estruturam e funcionam, o que ajudaria a refletir sobre suas falências e contribuiria para estabelecer os pontos que levam a sua desconexão com os cidadãos.

\section{GRÁFICO 1}

Nível de confiança nos partidos políticos por países

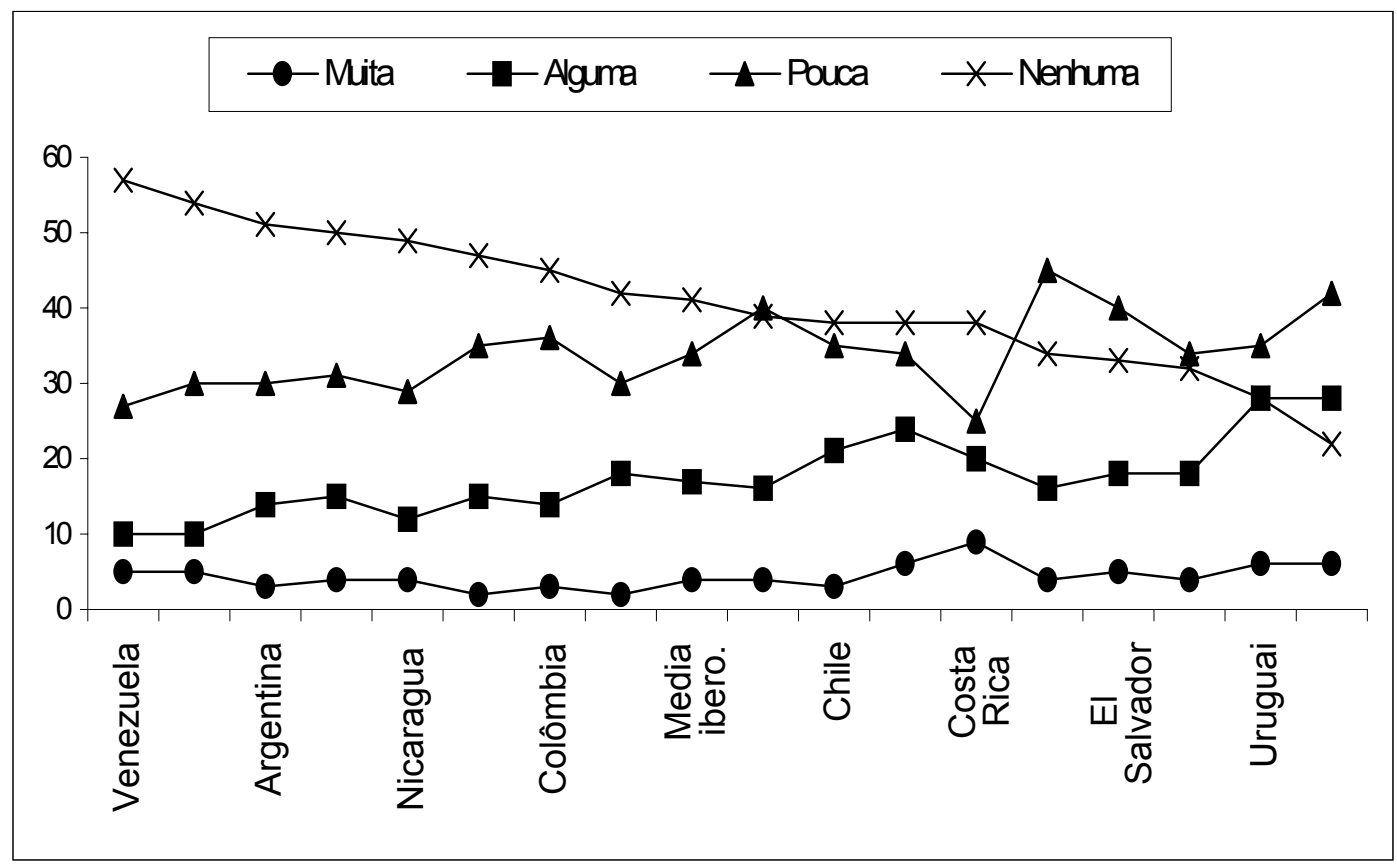




\section{QUADRO 4}

Confiança nos partidos políticos

\begin{tabular}{|l|r|r|r|r|r|}
\hline PAís & Muita & Alguma & Pouca & Nenhuma & $(\mathrm{N})$ \\
\hline $\begin{array}{l}\text { Média Ibero- } \\
\text { americana }\end{array}$ & $\mathbf{4}$ & $\mathbf{1 7}$ & $\mathbf{3 4}$ & $\mathbf{4 1}$ & $\mathbf{1 7 9 0 1}$ \\
\hline Venezuela & 5 & 10 & 27 & 57 & 1200 \\
\hline Equador & 5 & 10 & 30 & 54 & 1200 \\
\hline Argentina & 3 & 14 & 30 & 51 & 1264 \\
\hline Panamá & 4 & 15 & 31 & 50 & 1000 \\
\hline Nicarágua & 4 & 12 & 29 & 49 & 1000 \\
\hline Peru & 2 & 15 & 35 & 47 & 1045 \\
\hline Colômbia & 3 & 14 & 36 & 45 & 1200 \\
\hline Bolívia & 2 & 18 & 30 & 42 & 794 \\
\hline Brasil & 4 & 16 & 40 & 39 & 1000 \\
\hline Chile & 3 & 21 & 35 & 38 & 1200 \\
\hline Paraguai & 6 & 24 & 34 & 38 & 600 \\
\hline Costa Rica & 9 & 20 & 25 & 38 & 1000 \\
\hline Guatemala & 4 & 16 & 45 & 34 & 1000 \\
\hline El Salvador & 5 & 18 & 40 & 33 & 1000 \\
\hline Honduras & 4 & 18 & 34 & 32 & 1000 \\
\hline Uruguai & 6 & 28 & 35 & 28 & 1199 \\
\hline México & 6 & 28 & 42 & 22 & 1200 \\
\hline
\end{tabular}

Pergunta: Você diria que tem muita, alguma, pouca ou nenhuma confiança nos partidos políticos?

* Eliminaram-se os não sabe/não responde.

Fonte: Elaboração própria a partir de dados do Latinobarómetro 1998.

\section{GRÁFICO 2}

O funcionamento dos países e o papel dos políticos

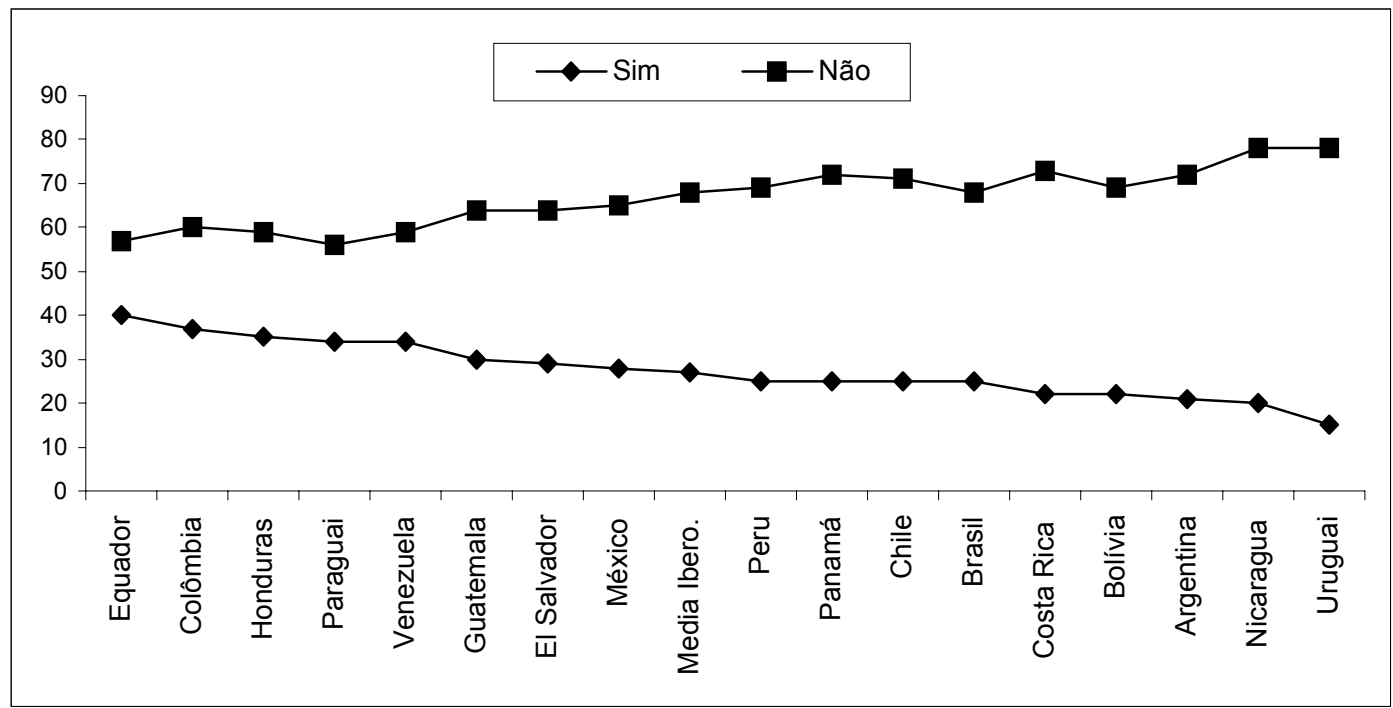




\section{QUADRO 5}

Porcentagem média de participação política

\begin{tabular}{|l|c|c|c|}
\hline PAís & Sim & Não & $(N)$ \\
\hline Média Ibero-americana & $\mathbf{2 7}$ & $\mathbf{6 8}$ & $\mathbf{1 7 7 6 7}$ \\
\hline Equador & 40 & 57 & 1200 \\
\hline Colômbia & 37 & 60 & 1200 \\
\hline Honduras & 35 & 59 & 1011 \\
\hline Paraguai & 34 & 56 & 575 \\
\hline Venezuela & 34 & 59 & 1200 \\
\hline Guatemala & 30 & 64 & 1000 \\
\hline El Salvador & 29 & 64 & 1010 \\
\hline México & 28 & 65 & 1105 \\
\hline Peru & 25 & 69 & 1054 \\
\hline Panamá & 25 & 72 & 1021 \\
\hline Chile & 25 & 71 & 1200 \\
\hline Brasil & 25 & 68 & 1001 \\
\hline Costa Rica & 22 & 73 & 1007 \\
\hline Bolívia & 22 & 69 & 796 \\
\hline Argentina & 21 & 72 & 1196 \\
\hline Nicarágua & 20 & 78 & 1002 \\
\hline Uruguai & 15 & 78 & 1189 \\
\hline Pergunta:Peloquevoce & & \\
\hline
\end{tabular}

Pergunta: Pelo que você sabe ou ouviu dizer, acredita que é possível que o país funcione sem políticos?

* Eliminaram-se os não sabe/não responde.

Fonte: Elaboração própria a partir de dados do Latinobarómetro 1998.

\section{QUADRO 6}

\section{Porcentagem média de participação política*}

\begin{tabular}{|l|l|l|l|l|l|}
\hline País & Média & Voto & País & Media & Voto \\
\hline Colômbia & 34,8 & Voluntário & Honduras & 62,1 & Obrigatório \\
\hline Guatemala & 36,5 & Obrigatório & Equador & 64,4 & Obrigatório \\
\hline R.Dominicana & 49,8 & Obrigatório & Venezuela & 66,6 & Obrigatório \\
\hline México & 52,2 & Obrigatório & Brasil & 71,9 & Obrigatório \\
\hline El Salvador & 53,8 & Obrigatório & Nicarágua & 74,5 & Voluntário \\
\hline Paraguai & 54,9 & Obrigatório & Argentina & 80,7 & Obrigatório \\
\hline Bolívia & 57,5 & Obrigatório & Costa Rica & 80,8 & Obrigatório \\
\hline Peru & 59,3 & Obrigatório & Chile & 84,1 & Obrigatório \\
\hline Panamá & 61,5 & Obrigatório & Uruguai & 89,3 & Obrigatório \\
\hline
\end{tabular}

* Porcentagem de voto sobre o total da população em idade legal de votar.

Fonte: IDEA (1997). Voter turnout from 1945 to 1997: a global report on political participation Stokholm. International Institute for Democracy and Electoral Assistance. 


\section{GRÁFICO 3}

Porcentagem média de participação política*

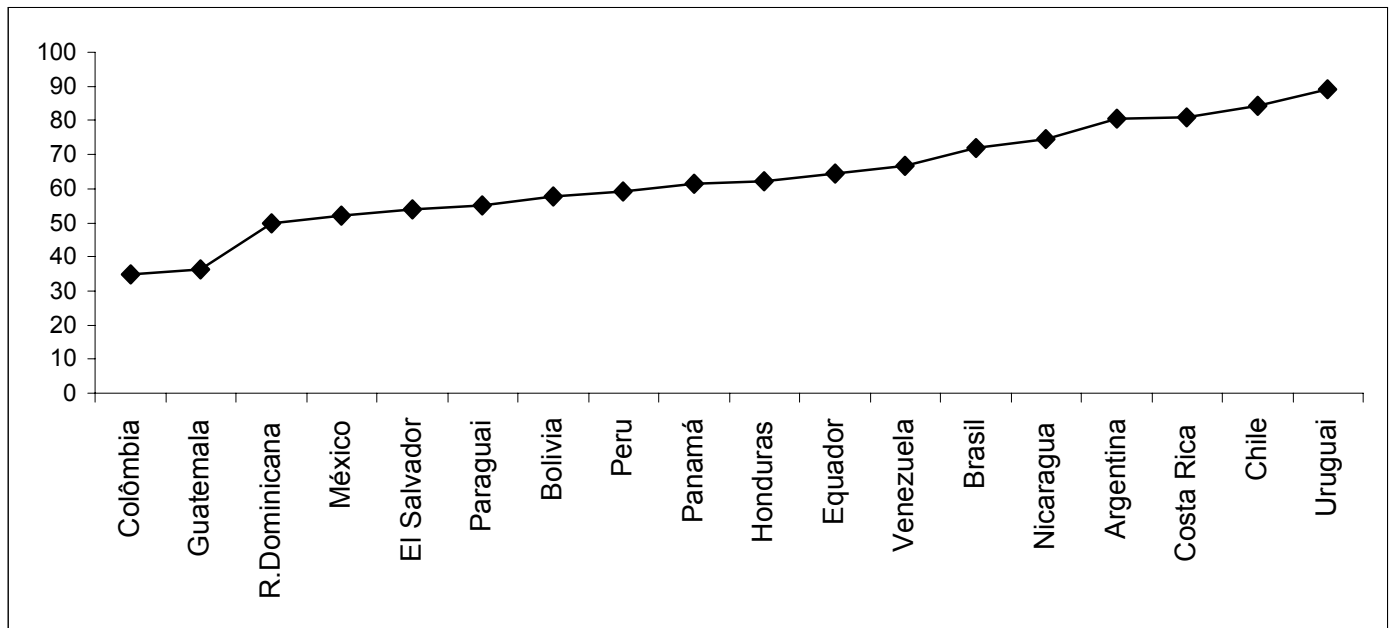

\section{GRÁFICO 4}

Importância que tem de votar*

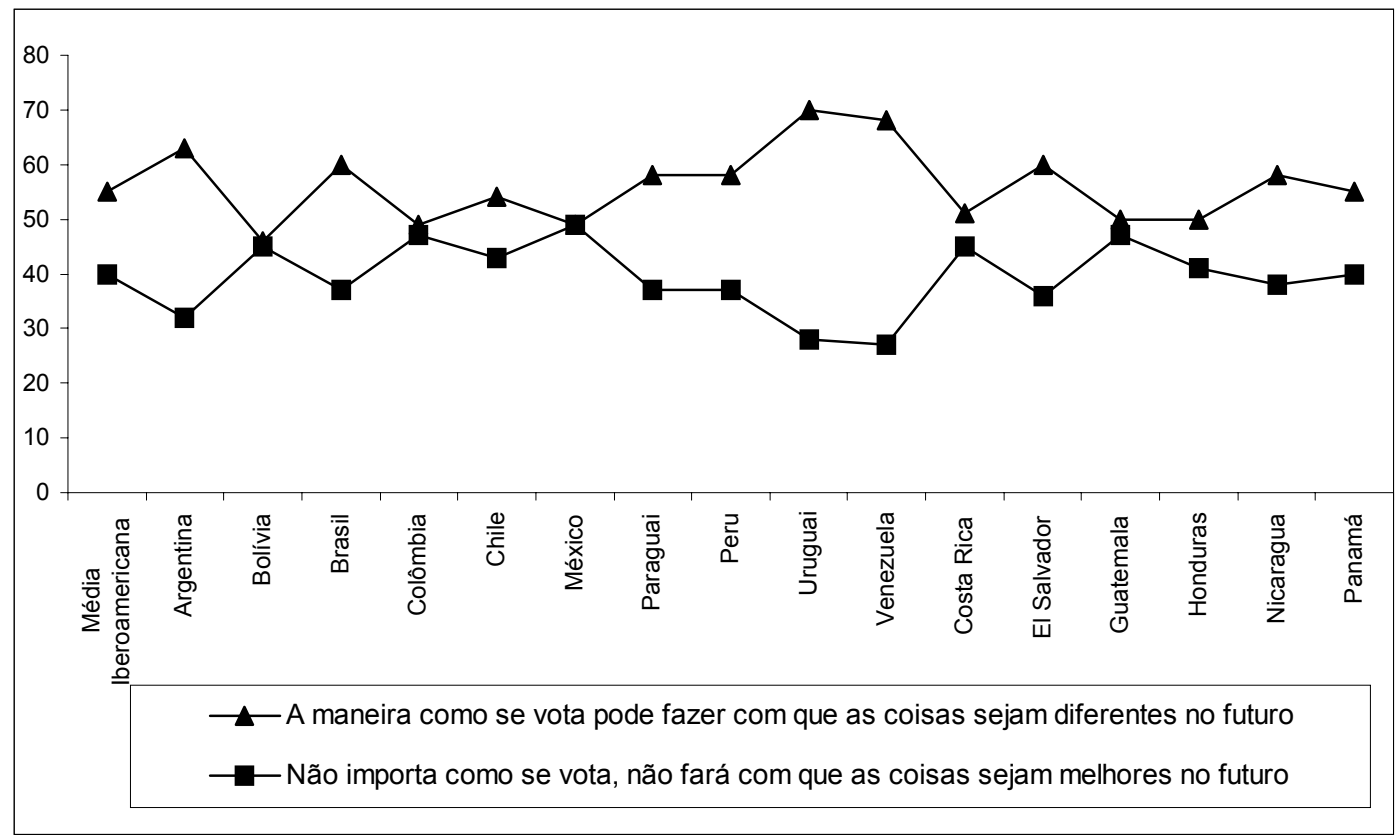


QUADRO 7

Importância de votar* (em porcentagens)

\begin{tabular}{|l|c|c|c|}
\hline \multicolumn{1}{|c|}{ PAís } & $\begin{array}{c}\text { A maneira como se vota } \\
\text { pode fazer com que as } \\
\text { coisas sejam diferentes } \\
\text { no futuro. }\end{array}$ & $\begin{array}{c}\text { Não importa como se vota, } \\
\text { não fará com que as coisas } \\
\text { sejam melhores } \\
\text { no futuro. }\end{array}$ & (N) \\
\hline Bolívia & 46 & 45 & 764 \\
\hline Colômbia & 49 & 47 & 1200 \\
\hline México & 49 & 49 & 1200 \\
\hline Guatemala & 50 & 47 & 1000 \\
\hline Honduras & 50 & 41 & 1000 \\
\hline Costa Rica & 51 & 45 & 1000 \\
\hline Chile & 54 & 43 & 1200 \\
\hline Panamá & 55 & 40 & 1000 \\
\hline Média Ibero-americana & 55 & 40 & 17902 \\
\hline Paraguai & 58 & 37 & 600 \\
\hline Peru & 58 & 37 & 600 \\
\hline Nicarágua & 58 & 38 & 1000 \\
\hline El Salvador & 60 & 36 & 1000 \\
\hline Brasil & 60 & 37 & 1000 \\
\hline Argentina & 63 & 32 & 1264 \\
\hline Venezuela & 68 & 27 & 1200 \\
\hline Uruguai & 70 & 28 & 1199 \\
\hline
\end{tabular}

Pergunta: Algumas pessoas dizem que a maneira como se vota pode fazer com que as coisas sejam diferentes no futuro. Outros dizem que independentemente de como se vota, não fará com que as coisas sejam melhores no futuro. Qual das frases está mais perto de sua maneira de pensar?

*Não foram levados em conta os não sabe/ não responde. Esta pergunta foi eliminada no caso do Equador devido a um erro em sua aplicação.

Fonte: Elaboração própria a partir de dados do Latinobarómetro 1998.

\section{BIBLIOGRAFIA}

ALCÁNTARA SÁEZ, Manuel. (1994) Análisis comparado del papel de los partidos en los procesos de transición política. In DUTRÉNIT, Silvia \& VALDÉS, Leonardo (eds.). El fin de siglo y los partidos políticos en América Latina. México, Instituto Mora e Universidad Autónoma Metropolitana.

(1996) Elecciones, electores y partidos en América Latina en la década de 1990. América Latina Hoy, 13 (maio): 7-16. Salamanca e Madri, Instituto de Estudios de Iberoamérica y Portugal/SEPLA.

(1997) Las tipologías y funciones de los partidos políticos. In: Vários autores. Curso de Partidos Politicos. Madri, AKAL Universitaria. p.37-57.

.(1999) Sistemas Políticos de América Latina. Vol I e II. Madri, Tecnos.

ALCÁNTARA SÁEZ, Manuel \& FREIDENBERG, Flavia. (2001) Partidos políticos de América Latina. Salamanca, Ediciones de la Universidad de Salamanca. 
ALDRICH, John. (1995) Why Parties? The Origin and Transformation of Political Parties in America. Chicago e Londres, The University of Chicago Press.

ÁlVAREZ, Angel. E. (1997) Los dineros de la política. Competencia en el mercado político e intervención del Estado. Caracas, Universidad Central de Venezuela. Facultad de Ciencias Jurídicas y Políticas. Instituto de Estudios Políticos.

COTARELO, Ramón. (1985) Los partidos políticos. Madri, Alianza.

CAVAROZZI, Marcelo. (1995) Los partidos políticos latinoamericanos: sus configuraciones históricas y su papel en las transiciones recientes. In: ALCÁNTARA, Manuel \& CRESPO, Ismael. (eds). Los límites de la consolidación democrática en América Latina. Salamanca, Ediciones Universidad de Salamanca.

COPPEDGE, Michael. (1994) Strong Parties and Lame Ducks. Presidential Partyarchy and Factionalism in Venezuela. Stanford, Stanford University Press.

DEL CASTILLO, Pilar \& ZOVATTO, Daniel. (1998) La financiación de la política en Iberoamérica. San José de Costa Rica, IIDH- CAPEL.

DI TELLA, Tulio. (1993) Historia de los partidos políticos en América Latina. Siglo XX. México, Fondo de Cultura Económica.

DOWNS, Anthony. (1957) An Economic of Theory of Democracy. Harper and Bros.

DUTRÉNIT, Silvia. (ed). (1998) Huellas de las transiciones políticas. Partidos y elecciones en América Latina. México, Instituto Mora.

DUTRÉNIT, Silvia \& VALDÉS, Leonardo. (1994) El fin de siglo y los partidos políticos en América Latina. México, Instituto Mora-UAM Iztapalapa.

DUVERGER, Maurice. (1951) Les partis politiques. Paris, Librairie Armand Colin. (Edição castelhana consultada: Los partidos políticos. México, Fondo de Cultura Económica, 1992).

ELDSERVELD, Samuel. (1964) Political Parties. An Behavioral Analysys. Chicago, Rand McNally.

FERNÁNDEZ RUBIO, Delia. (1997) El financiamiento de los partidos políticos. Buenos Aires, CIEDLA.

FREIDENBERG, Flavia \& ALCÁNTARA SÁEZ, Manuel. (2001) Los dueños del poder: Partidos Políticos en Ecuador 1978-2000. Quito, Flacso- Sede Ecuador.

GARRETÓN, Manuel Antonio (ed). (1993) Los partidos y la transformación política de América Latina. Santiago, CLACSO y FLACSO- Chile.

JIMENEZ POLANCO, Jackeline. (1995) El Partido Revolucionario Dominicano (PRD): La faccionalización de un partido carismático. In: LÓPEZ Nieto, L.; GILLIESPIE, R. \& WALTER, M (comp.). Política Faccional y Democratización. Madri, Centro de Estudios Constitucionales.

KATZ, Richard \& MAIR, Peter. (1990) Three Faces of Party Organization: Adaptation and Change. Trabalho preparado para o XII World Congress of Sociology realizado em Madri entre 9-13 julho. Mimeo.

(1995) Changing Models of Party Organization and Party Democracy. The Emergence of the Cartel Party. Party Politics, 1(1):5-29.

KIRCHHEIMER, Otto. (1966) The transformation of the Western European Party System. In: LAPALOMBARA \& WINER, M. Political Parties and Political Development. Princeton, Princenton University Press.

LAAKSO, M. \& TAAGEPERA, R. (1979) Effective number of parties. A measure with application to West Europe. Comparative Political Studies, 12:3-27. 
LEVITSKY, Steve. (1997) Crisis, adaptación partidaria y estabilidad del régimen en la Argentina: el caso del peronismo (1989-1995). Revista de Ciencias Sociales, 6:85-131(setembro).

LIPSET, Seymour. M. \& ROKKAN, Stein. (1967) Party, Systems and Voter Alignements.. Nova York, Free Press. (Tradução para o espanhol consultada: Estructura de división, sistemas de partidos y alineamientos electorales, in BATTLE, A. Diez textos básicos de Ciencia Política. Barcelona, Airel.1992).

MAINWARING, Scott \& SCULLY, Timothy (eds.). (1995) Building Democratic Institutions. Stanford, Stanford University Press.

MAINWARING, Scott \& SOBERG SHUGART, Michael (eds). (1997) Presidencialism and Democracy in Latin America. Cambridge e Nova York, Cambridge University Press.

MALAMUD, C. (1995) Partidos políticos y elecciones en América Latina y la península. Madri, Instituto Universitario Ortega y Gasset.

MANZ, T. \& ZUAZO, M. (coords). (1998) Partidos políticos y representación en América Latina. Caracas, Nueva Sociedad, ILIDIS, Friedrich Ebert Stiftung-FES.

MAYORGA, René. (1995) Antipolítica y neopopulismo. La Paz, CEBEM.

MORGENSTERN, Scott. (1996) The electoral connection and the legislative process in Latin America: Factions, Parties and Alliances in theory and practice. San Diego, Dissertação de Ph.D. University of California.

NOHLEN, Dieter. (1993) Sistemas Electorales y Sistemas de partidos. México, FCE.

PANEBIANCO, Angelo. (1982) Modelli di partito. Bologna, Societa Editrice il Mulino (Edição castelhana consultada: PANEBIANCO, Angelo (1990) Modelos de partido. Madri, Alianza Editorial).

PERELLI, Carina; Picado, Sonia \& ZOVATTO, Daniel (comps). (1995) Partidos y clase política en los 90. San José, IDDH-CAPEL.

RAMOS ROLLÓN, María Luisa. (1998) La financiación de los partidos políticos en América Latina: Estado actual y propuestas de reforma. Revista de Estudios Políticos, 102 (outubro-dezembro):321337. (Madrid: Centro de Estudios Constitucionales).

RAE, Douglas. (1977) Leyes electorales y sistemas de partidos políticos. Madri, CITEP.

SANI, Giacomo e SHABAD, Goldie. (1986) ¿Adversarios o competidores? La polarización del electorado. In: LINZ, Juan José \& MONTERO, José Ramón. Crisis y cambio: Electores y partidos en la España de los ochenta. Madri, Centro de Estudios Constitucionales.

SARTORI, Giovanni. (1976) Partidos y sistemas de partidos. Madri, Alianza. (Edição consultada, 1992).

SARTORI, Giovanni \& Sani, Giacomo. (1992) Polarización, Fragmentación y competición en las democracias occidentales. In: SARTORI, G. Partidos y Sistemas de Partidos. Madri, Alianza.

VON BEYME, Klaus. (1986) Los partidos políticos en las democracias occidentales. Madri, Centro de Investigaciones Sociológicas.

WEBER, Max. (1992) Economía y Sociedad. México, Fondo de Cultura Económica.

Recebido para publicação em maio de 2002

Tradução de Pedro Maia Soares 